\title{
Ex vivo enrichment of circulating anti-tumor $T$ cells from both cutaneous and ocular melanoma patients: clinical implications for adoptive cell transfer therapy
}

\author{
Tonia Mazzarella $\cdot$ Valeria Cambiaghi $\cdot$ Nathalie Rizzo $\cdot$ Lorenzo Pilla $\cdot$ \\ Danilo Parolini $\cdot$ Elena Orsenigo $\cdot$ Annalisa Colucci · Giulio Modorati · \\ Claudio Doglioni · Giorgio Parmiani · Cristina Maccalli
}

Received: 18 July 2011 / Accepted: 29 November 2011 / Published online: 30 December 2011

(C) The Author(s) 2011. This article is published with open access at Springerlink.com

\begin{abstract}
Tumor-infiltrating lymphocytes (TILs) have been successfully used for adoptive cell transfer (ACT) immunotherapy; however, due to their scarce availability, this therapy is possible for a limited fraction of cutaneous melanoma patients. We assessed whether an effective protocol for ex vivo T-cell expansion from peripheral blood mononuclear cells (PBMCs), suitable for ACT of both cutaneous and ocular melanoma patients, could be identified. PBMCs from both cutaneous and ocular melanoma patients were stimulated in vitro with autologous, irradiated melanoma cells (mixed lymphocyte tumor cell culture; MLTCs) in the presence of IL-2 and IL-15 followed by the rapid expansion protocol (REP). The functional activity of these $\mathrm{T}$ lymphocytes was characterized and compared with
\end{abstract}

Giorgio Parmiani and Cristina Maccalli equally contributed to this study.

Electronic supplementary material The online version of this article (doi:10.1007/s00262-011-1179-z) contains supplementary material, which is available to authorized users.

T. Mazzarella $\cdot$ V. Cambiaghi $\cdot$ L. Pilla $\cdot$ G. Parmiani

C. Maccalli $(\bowtie)$

Unit of Immuno-Biotherapy of Melanoma and Solid Tumors, Division of Molecular Oncology, San Raffaele Scientific Institute, Via Olgettina, 58, 20132 Milan, Italy

e-mail: cristina.maccalli@hsr.it

N. Rizzo · C. Doglioni

Unit of Pathology, San Raffaele Hospital, Milan, Italy

D. Parolini · E. Orsenigo

Unit of Gastro-Enterological Surgery, Department of Oncology,

San Raffaele Hospital, Milan, Italy

A. Colucci · G. Modorati

Unit of Ophthalmology, San Raffaele Hospital, Milan, Italy that of TILs. In addition, the immune infiltration in vivo of ocular melanoma lesions was analyzed. An efficient in vitro MLTC expansion of melanoma reactive $\mathrm{T}$ cells was achieved from all PBMC's samples obtained in 7 cutaneous and ocular metastatic melanoma patients. Large numbers of melanoma-specific $\mathrm{T}$ cells could be obtained when the REP protocol was applied to these MLTCs. Most MLTCs were enriched in non-terminally differentiated $\mathrm{T}_{\mathrm{EM}}$ cells homogeneously expressing co-stimulatory molecules (e.g., NKG2D, CD28, CD134, CD137). A similar pattern of anti-tumor activity, in association with a more variable expression of co-stimulatory molecules, was detected on short-term in vitro cultured TILs isolated from the same patients. In these ocular melanoma patients, we observed an immune infiltrate with suppressive characteristics and a low rate of ex vivo growing TILs (28.5\% of our cases). Our MLTC protocol overcomes this limitation, allowing the isolation of $\mathrm{T}$ lymphocytes with effector functions even in these patients. Thus, anti-tumor circulating PBMC-derived $\mathrm{T}$ cells could be efficiently isolated from melanoma patients by our novel ex vivo enrichment protocol. This protocol appears suitable for ACT studies of cutaneous and ocular melanoma patients.

Keywords Cutaneous melanoma - Ocular melanoma . T-cell responses $\cdot$ Immunotherapy

\section{Introduction}

The incidence of melanoma has increased over the past three decades [1]. In addition, this tumor is resistant to standard therapies with a life expectancy of less then 1 year for metastatic melanoma patients [2]. Tough new targeted therapies [3] and immunotherapy trials [4, 5], however, suggest 
that survival of melanoma patients may be considerably improved in the near future. Ocular melanoma, though infrequent, is a very aggressive disease with a dismal prognosis since $50 \%$ of patients die from metastatic disease $[6,7]$. Notably, the biological and molecular profiles of ocular melanoma showed relevant differences compared to cutaneous melanoma, with the first type of tumor commonly developing liver metastasis. For example, the mutated BRAF, which is detected in up to $62 \%$ of cutaneous melanoma and represents a novel target molecule [3], is rarely found in ocular melanoma [8]. Furthermore, the eye has been considered an "immune privileged" site maintained by a variety of immune suppressive mechanisms (e.g., TGF- $\beta$, IL-10, immune cells with negative regulatory functions) that can sustain the development of ocular tumors [9]. However, immunogenic intraocular tumors leading to the immune-mediated rejection have been documented in animal models [10-12]. It has been reported that the presence of either tumor-infiltrating lymphocytes (TILs) or tumorinfiltrating macrophages (TIMs) is associated with poor prognosis in uveal melanoma patients [9]. Thus, it remains to be ascertained if immune stimulation may favor or control the progression of ocular tumors. In fact, it has been shown in cutaneous melanoma that tumor cells can produce immuno-modulating factors, which exhaust or block the immune response and recruit immune cells with negative regulatory activity ( $\mathrm{T}$ regulatory cells, Tregs; myeloidderived suppressor cells, MDSCs; suppressive macrophages, M2) to a specific site $[13,14]$. Therefore, immunotherapeutic protocols that can modify and rescue anti-tumor immune responses need to be designed for both cutaneous and ocular melanoma patients.

Different active strategies have been used to induce antitumor immunity in cancer patients mainly based on the targeting of a variety of tumor-associated antigens (TAAs) by active therapy (vaccination) with peptide, protein or DNA/ RNA [15-17]. These vaccination strategies, while increasing systemic anti-tumor immune responses, resulted in limited clinical outcome [16-18], though a recently performed peptide-based phase II vaccination trial documented an increase in the median overall survival in metastatic melanoma patients [5]. On the other hand, the adoptive T-cell therapy (ACT) can overcome the suppressive tumor milieu by using immune cells with cancer specificity grown outside of the patient and infused in large numbers following pre-conditioning by chemotherapy, alone or in combination with patient total body irradiation [19-21].

ACT with TILs isolated from metastatic melanoma lesions led to objective tumor regression in $49-72 \%$ of patients with many long-term sustained responses [20, 21]. However, TILs can be exploited for ACT studies only in melanoma patients with resectable tumors and from which $\mathrm{T}$ cells can be expanded ex vivo (approximately $60-70 \%$ )
[20, 22]. A recent published analysis identified the parameters, such as age, sex and the type of systemic therapy, that can negatively influence the ex vivo expansion of TILs [22].

The persistence in vivo of the infused $\mathrm{T}$ cells was highly associated with clinical responses. The in vivo effectiveness of TILs was also associated with the differentiation state of the $\mathrm{T}$ cells, telomere length and CD27 expression, factors that are relevant for specific anti-tumor activity [23-25]). These results have been confirmed in a phase II clinical study showing high frequency of objective regressions in metastatic melanoma patients [26].

An alternative approach has been explored for patients without resectable lesions or with low number of TILs using autologous lymphocytes isolated from the peripheral blood genetically modified with genes encoding for antitumor T-cell receptors (TCRs) [19, 27, 28]. These studies showed encouraging clinical responses by using T-cell receptor (TCR) specific for differentiating (Melan-A/ MART-1, CEA) or cancer testis (MAGE-A3, NY-ESO-1) antigens, which could be applied to tumors having different histological origins [27]. This strategy however permits the targeting of only a single tumor antigen by the engineered $\mathrm{T}$ lymphocytes with the risk of tumor variants selection. Further efforts are therefore needed to develop ACT protocols, which employ the use of T lymphocytes with the ability to target a wider range of tumors and have a greater potential of tumor site migration. This would result in treatment for a larger number of cancer patients.

To this aim, we characterized anti-melanoma immune responses of $\mathrm{T}$ cells isolated both from the peripheral blood and from the TILs of cutaneous and ocular melanoma patients. As a result, we identified a new protocol that allows for the in vitro enrichment and expansion in large scale of $\mathrm{T}$ lymphocytes obtained from PBMCs, which were compared to those obtained with TILs. Furthermore, this protocol benefits from the stimulation with the autologous tumor cells, which in turn leads to the selection of $\mathrm{T}$ cells directed against multiple TAAs. Therefore, this protocol would be suitable for ACT clinical studies in the vast majority of both cutaneous and ocular melanoma patients particularly when TILs are not available.

\section{Materials and methods}

\section{Cell lines, PBMCs and TILs}

Melanoma cell lines were established in vitro from surgically resectable tumor lesions from both cutaneous (\#1061, 1067, 2710, 4478D, 49318, 0342, 25368 and $7 \mathrm{mel}$ ) and ocular (\#2130, 4330, 4022, 1141, 37165, 48409 and 15765) melanoma patients. The informed consent was obtained 
from all the subjects enrolled in this study. Other cutaneous melanoma lines used for this study were JOFR-IA, DAJU (kindly provided by Dr Pierre Coulie, de Duve Institute, Université Catholique de Louvain, Brussels, Belgium), 501 mel, a gift of Dr. Paul F. Robbins, (National Cancer Institute, NIH, Bethesda, MD) and the 15392 line provided by Dr. Chiara Castelli (Istituto Nazionale Tumori, Milan, Italy). These melanoma lines were cultured in RPMI 1640 (Biowittaker, Lonza, Treviglio, Italy) supplemented with $10 \%$ FBS (Lonza), $20 \mathrm{mM}$ HEPES, penicillin $(200 \mathrm{U} / \mathrm{ml})$, streptomycin (200 ug/ml) and $2 \mathrm{mM}$ Glutamax (Invitrogen, Carlsbad, CA).

Melanoma cell lines used for the stimulation in vitro of autologous PBMCs were maintained in 48-h cultures with RPMI plus $10 \%$ human serum (HS).

Other cell lines used were the lymphoblastoid cell line T2 and HLA-A3-C1R, the erythroblastoid cell lines K562 (American Type Cell Culture, ATCC-LGC, LGC Standards) and the EBV-B cell line 1869 [29].

PBMCs were obtained by Ficoll density gradient centrifugation (Ficoll-Paque PLUS, GE Healthcare Bio-Science $\mathrm{Ab}$, Uppsala, Sweden) of peripheral blood drawn from both ocular and cutaneous melanoma patients, while TILs were isolated from melanoma lesions. The MHC class I and II typing of PBMCs of melanoma patients was performed by sequence-specific oligonucleotide PCR.

\section{Immunohistochemistry}

Surgical specimens from ocular melanoma patients ( $N=10$ primary uveal melanoma) were fixed in formalin and embedded in paraffin. Immunohistochemistry (IHC) analysis was done on 5- $\mu \mathrm{m}$ tissue sections, and the staining was performed with a sensitive non-biotin detection system (Novo Link polymer, Novacastra) and with diaminobenzidine or double stain with diaminobenzidine and alkaline phosphatase-fast red development. Heat-induced antigen retrieval was done with Tris-EDTA $(\mathrm{pH} 9.0)$ in water bath for $30 \mathrm{~min}$. The monoclonal antibodies (mAbs) used were directed against the following antigens: antiCD3, anti-CD4, anti-CD25 and anti-CD163 (Novocastra), anti-CD8 (DB Biotech), anti-FOXP3 (CNIO Madrid), anti-GATA3 (Becton-Dickinson; BD Biosciences, San Jose, CA, USA) and anti-T-Bet (Santa Cruz Biotechnology, Inc.). Staining was carried out by an automatic immunostainer (Autostainer 480, Thermofisher), and immunostained slides were digitalized with the Aperio (Aperio Technologies, Vista, CA, USA) slide scanner and corresponding $1 \mathrm{~mm}^{2}$ of tumor areas on serial sections was selected. Immunolabeled cells were counted and expressed as percentage on total cells obtained using the IHC Nuclear Image Analysis algorithm of the Spectrum Plus software (Aperio).
Flow cytometry analysis

The HLA class I and II expression by melanoma cell lines was measured by flow cytometry using anti-HLA-A2, HLA-ABC and HLA-DR mAbs conjugated with fluorescein isothiocyanate (FITC), phycoerytrin (PE) and peridinin chlorophyll protein (PerCP)-Cy-5.5 (BD Biosciences), respectively. For melanoma line immuno-phenotyping, the following mAbs were used: anti-MICA, anti-MICB and anti-ULBP1-4 (provided by Amgen, Thousand Oaks, CA, USA), anti-MAGE 57B (provided by Dr. Giulio Spagnoli, University of Basel, Switzerland), anti-NY-ESO-1 E978 (Zymed Laboratories, San Francisco, CA, USA), anti-Survivin (SVV) 8E2 (Thermo Fisher Scientific), anti-Melan-A/ MART-1 M2-7C10, anti-gp100 HMB45 and anti-IL13Ra2 B-D13 (Santa Cruz Biotechnology) and the polyclonal Ab anti-COA-1 (Protein Expert; Marseille, France). The goat anti-mouse IgG PE conjugated or the goat anti-rabbit IgG FITC (Dako Italia SpA, Milan, Italy) was used as secondary Abs.

Phenotypic characterization of T-cell cultures was done by the multiparametric flow cytometry analysis using the following mAbs: TCR $\gamma / \delta$, CD4, CD62L, CD57 and IFN- $\gamma$ FITC conjugated; TCR $\alpha / \beta$, CCR7, CD127, CD107a and perforin PE conjugated; NKG2D, CD27, CD56 and CD137 allophycocyanin (APC) conjugated; CD8 and CD16 APCH7 conjugated; CD25 APC-Cy7 conjugated; CD134 PECy5 conjugated; CD45RO PE-Cy7 conjugated; CD45RA PE Texas Red (ECD) conjugated; CD28 PerCpCy5.5 and CD3 Pacific Blue (PB) conjugated (BD Biosciences).

Lymphocytes were incubated with mAbs to surface markers at $4{ }^{\circ} \mathrm{C}$ for $30 \mathrm{~min}$, washed with PBS 5\% FBS buffer and fixed with $0.5 \%$ paraformaldehyde. Intracellular staining was performed using BD Cytofix/Cytoperm Fixation/Permeabilization Solution Kit (BD Bioscience Pharmingen). Data were acquired on the LSRII flow cytometer (BD) and analyzed with FCS Express Software (Denovo Software, Los Angeles, CA, USA) or Kaluza Software (Beckman Coulter, Brea, CA, USA). Results are expressed as MRFI, representing the ratio between the mean fluorescence intensity of cells stained with the selected $\mathrm{mAb}$ and that of cells stained with isotype-matched control mouse immunoglobulins or, in the case of multiparametric phenotype analysis, as the percentage of positive cells subtracted above background.

\section{Mixed lymphocytes tumor cell culture (MLTC)}

PBMCs isolated from melanoma patients were thawed and incubated overnight at $37^{\circ} \mathrm{C}$. PBMCs $\left(10^{6}\right.$ cells/well $)$ were cultured in the presence of autologous irradiated (150 Gy) melanoma cells at a lymphocyte to tumor ratio of 5:1 in 24well plates with X-VIVO15 and 5\% HS. Different cytokine 
combinations were added to these MLTCs in order to select the most suitable in vitro culture conditions in terms of $\mathrm{T}$ lymphocyte expansion and efficiency in tumor cell recognition: (1) $120 \mathrm{IU} / \mathrm{ml}$ rhIL-2 (Proleukin, Novartis Farma, Origgio, Italy); (2) $120 \mathrm{IU} / \mathrm{ml}$ rhIL-2 and $10 \mathrm{ng} / \mathrm{ml} \mathrm{rhIL}-15$ (Peprotech, Rocky Hill, NJ, USA); (3) $10 \mathrm{ng} / \mathrm{ml}$ rhIL-15; (4) $5 \mathrm{ng} / \mathrm{ml}$ rh-IL-7 (Peprotech); (5) $120 \mathrm{IU} / \mathrm{ml}$ rhIL-2 and $5 \mathrm{ng} / \mathrm{ml}$ rhIL-7; (6) $120 \mathrm{IU} / \mathrm{ml}$ rhIL-2 and $10 \mathrm{ng} / \mathrm{ml}$ rhIL-21 (Peprotech); (7) $10 \mathrm{ng} / \mathrm{ml}$ rhIL-21 alone. Fresh medium containing the above indicated cytokines was replaced every 3 days. These MLTCs were stimulated weekly with irradiated autologous melanoma cells, and their reactivity was tested starting from the 3 rd week of culture.

\section{ELISPOT assay}

To determine the specific recognition of tumor cells by $\mathrm{T}$ lymphocytes, the ELISPOT assay was performed as previously described [30]. Anti-human IFN- $\gamma$ mAb (1-D1 K), the secondary biotinylated anti-IFN- $\gamma$ mAb (7-B6-1) and the secondary alkalin phosphatase-streptavidin were purchased from Mabtech (Naka Stand, Sweden). The specificity of T-cell recognition was determined by the inhibition of the IFN- $\gamma$ release after pre-incubation of target cells with the W6/32 (anti-HLA class I) or L243 (anti-HLA class II DR molecules) mAbs (ATCC). In addition, T lymphocytes were pre-treated with the anti-NKG2D mAb (clone M585, kindly provided by Amgen) before the incubation with target cells. T lymphocytes incubated with phytohemagglutinin (PHA) and concanavalin-A (ConA) (Sigma-Aldrich) were used as a positive control for IFN $-\gamma$ secretion. The cell lines T2 $\left(\mathrm{HLA}^{+}{ }^{+}\right), 1869$ EBV-B (HLA-A3 ${ }^{+}$and A24 ${ }^{+}$) and C1R (HLA-A3 +) were used as antigen-presenting cells and pulsed with $10 \mu \mathrm{g} / \mathrm{ml}$ of Melan-A/MART-1-, gp100-, MAGE-A2- and A3-, NY-ESO-1- or SVV-HLA-A2restricted peptides (JPT Peptide technologies, Berlin, Germany) or MAGE-A1-, gp100- and COA-1-HLA-A3restricted peptides [29, 30]. In addition, HLA-A3-C1R cells transiently transfected by electroporation with expression vectors (pcDNA3) coding for COA-1 and SVV antigens were used as target cells as well.

Statistical analysis of the differences between means in the cytokine release assays was performed using two-tailed $t$ test $(P<0.05)$.

In vitro rapid expansion of T lymphocytes

The rapid expansion of TILs or of MLTC-derived T cells was performed using the rapid expansion protocol (REP) as previously described by Dudley et al. [31]. Briefly, T lymphocytes were cultured in T25 flasks in X-VIVO15, 5\% HS and in the presence of 200-fold excess of irradiated (50 Gy) feeder cells that were isolated and pooled from three healthy donors. On day 4, $30 \mathrm{ng} / \mathrm{ml}$ of anti-CD3 (OKT-3, Ortho Clinical Diagnostics, Rochester, USA) mAb and $6,000 \mathrm{U} / \mathrm{ml}$ of rh-IL-2 were added. The culture media containing rh-IL-2 was replaced every 3 days. At day 14 following the in vitro expansion, the specific reactivity by $\mathrm{T}$ lymphocytes against autologous and/or HLA-matched allogeneic melanoma lines and melanoma-associated epitopes was determined by IFN- $\gamma$ release assay (ELISPOT) as described above.

Assessment of the cytotoxic activity

The cytotoxic activity of $\mathrm{T}$ lymphocytes was determined by the CD107a mobilization assay [32] and intracellular detection of perforin. $\mathrm{T}$ lymphocytes were co-cultured with autologous or allogeneic HLA-matched tumor cells at a 4:1 ratio in polystyrene tubes. Control tubes contained lymphocytes alone or co-cultured with HLA-mismatched melanoma cells. Positive controls were comprised of cells stimulated with PHA/Con-A or OKT3. CD107a-PE (BD Pharmingen) $\mathrm{mAb}$ was added to the T-cell cultures. After $1 \mathrm{~h}$ of incubation at $37^{\circ} \mathrm{C}, 1 \mu \mathrm{l} /$ tube monesin (Golgi-Stop, BD Bioscience) was added as per kit protocol to the cultures then incubated at $37^{\circ} \mathrm{C}$ for an additional 3 or $5 \mathrm{~h}$. At the end of the incubation, time cells were stained for the surface markers $\mathrm{CD} 3$ and $\mathrm{CD} 8$, permeabilized and stained with anti-perforin PE and/or anti-IFN- $\gamma$ FITC mAbs (BD Pharmingen). Samples were then analyzed by flow cytometry as described above.

\section{Results}

Comparison of the efficiency of different cytokines in the isolation and in vitro expansion of anti-melanoma T lymphocytes

To isolate in vitro anti-melanoma $\mathrm{T}$ cells, mixed lymphocyte tumor cell cultures (MLTCs) were set up by stimulating PBMCs from melanoma patients with irradiated autologous melanoma cells. Initially, the efficacy of different cytokines, alone or in combination, on the in vitro growth of T lymphocytes was compared. To this aim, independent MLTCs from the cutaneous melanoma patient \#2710 were set up in the presence of the following cytokines: (1) rhIL-2; (2) rhIL-2 and rhIL-15; (3) rhIL-15; (4) rh-IL-7; (5) rhIL-2 and rhIL-7; (6) rhIL-2 and rhIL-21; and (7) rhIL-21. At day 21, the highest expansion rate of lymphocytes (105-fold increase of the T-cell number) was obtained with IL-2 alone (Fig. 1). Efficient expansion in vitro of $\mathrm{T}$ cells was also obtained by culturing the MLTCs with IL-2 and IL-15 (87.5-fold increase) or with IL-2 + IL-7 (68.4-fold increase) (Fig. 1). Interestingly, similar increases in the number of $\mathrm{T}$ cells were 


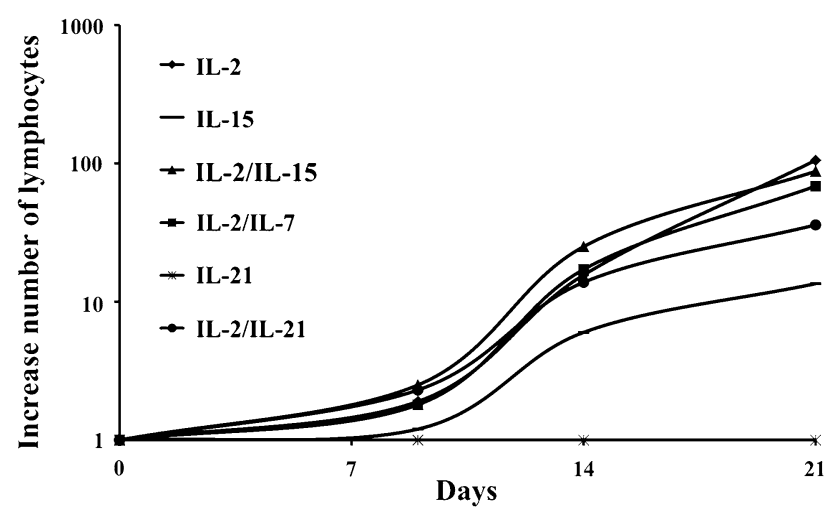

Fig. 1 Expansion in vitro of $\mathrm{T}$ lymphocytes cultured with different cytokines or their combinations. PBMCs $\left(1 \times 10^{6}\right.$ cells $)$ isolated from the cutaneous melanoma patient 2710 were stimulated in vitro with irradiated autologous tumor cells at 1:5 tumor cell lymphocyte ratio in the presence of cytokines indicated in the figure. Fresh medium was replaced every 3 days. T-cell growth was assessed at days 9, 14 and 21 . Results represent averages of triplicates of the fold increase number with $\mathrm{SD} \leq 10 \%$; statistical analysis of differences between means of fold of increase of T-cell numbers was performed by two-tailed $t$ test $(P \leq 0.01)$

observed when performing the MLTC with IL-2 and IL-15, followed for the second week of culture with IL-2 plus IL-7 (data not shown). The MLTC grown either with IL-2 plus IL-21 or with IL-15 alone led to a lower expansion of T cells (35.88 and 13.5-fold increase, respectively) (Fig. 1). No proliferation of $\mathrm{T}$ cells was observed in the presence of IL-21 alone (Fig. 1).

To assess the reactivity of these MLTCs against tumor cells, IFN- $\gamma$ release was determined by ELISPOT. As shown by the representative data in Fig. 2, T lymphocytes maintained in culture with IL-2 and IL-15 released the highest amount of IFN- $\gamma$ (n. 337 spots/5,000 cells) after the incubation with the autologous tumor cells (\#2710 mel) (Fig. 2b) compared to the other in vitro culture conditions (n. 38.5-199 spots/5,000 cells) of MLTCs (Fig. 2a, c, d). Specific inhibition of IFN- $\gamma$ release was observed after preincubation of the autologous tumor cells with the anti-HLA class I mAb (W6/32), not with the anti-HLA class II (L243) $\mathrm{mAb}$ (Fig. 2b). Similarly, the recognition of the HLAmatched (HLA-A*0201) allogeneic cutaneous melanoma line 501 mel was superior (n. 371 spots/5,000 cells; Fig. 2b) by culturing T cells with IL-2 plus IL-15 compared to the others cytokines or their combinations (20-205 n. spot/ 5,000 cells; Fig. 2a, c, d). Moreover, all the MLTCs (Fig. 2) failed to recognize the HLA-mismatched allogeneic cutaneous melanoma 15392 mel. No significant reactivity against the K562 line was detected for the MLTCs cultured with IL-2 plus IL-15 or IL-2 plus IL-21 (Fig. 2b, d), while IFN- $\gamma$ release, though at low levels (22 and 42 spots/5,000 cells, respectively), occurred following the incubation of the MLTCs cultured with IL-2 alone or IL-2 plus Il-7 with this cell line (Fig. 2a, c). Higher reactivity (195 spots/5,000 cells) against the K562 cell line as compared with the autologous melanoma (62 spots/5,000 cells) was observed by lymphocytes expanded in vitro with IL-15 alone, indicating that an enrichment of NK-type immune responses occurred in this MLTC (data not shown). Thus, IL-2 plus IL-15 led to the most efficient isolation and expansion in vitro of melanoma-specific $\mathrm{T}$ lymphocytes, and therefore, this cytokine combination was utilized for the subsequent ex vivo selection of anti-tumor T lymphocytes.

Identification of a new protocol to isolate in vitro $\mathrm{T}$ lymphocytes with specific reactivity against the autologous tumor

The MLTC-based protocol has been applied to activate and expand in vitro circulating $\mathrm{T}$ cells from cutaneous melanoma patients.

Independent MLTC cultures were set up from PBMCs isolated from 6 metastatic cutaneous melanoma patients (\#2710, 4478D, JOFR-IA, DAJU, 0342 and 7). T cells were stimulated weekly with irradiated autologous tumor cells in the presence of IL-2 and IL-15. Following the two rounds of in vitro stimulation (day 15), the tumor specificity of these MLTCs was assessed by IFN- $\gamma$ release (ELISPOT assay). Representative data of patients \#2710 are shown in Fig. 3a. In addition, results of patient \#4478D are shown in Fig. 1S Panel A of the supplementary online data. These T lymphocytes exhibit specific recognition of the autologous tumor lines (285 spots/5,000 cells for \#2710 Fig. 3a) with significant inhibition $(53 \% ; P \leq 0.001)$ of cytokine release after pre-treatment of target cells with the $\mathrm{W} 6 / 32 \mathrm{mAb}$. Instead, low inhibition (26\% for \#2710) of IFN- $\gamma$ release was found in the presence of the anti-MHC class II (L243) mAb (Fig. 3a).

Notably, the MLTC from the HLA-A*0201+ melanoma patient \#2710 specifically (92\% of inhibition in the presence of the W6/32 $\mathrm{mAb}$ ) recognized the HLA class I-matched allogeneic 501 mel line and the HLA-A*0201restricted Melan-A/MART-1-derived epitope (Fig. 3a). The evidence that the recognition of the Melan-A/MART-1derived epitope by this MLTC was weaker than the autologous and the allogeneic 501 mel tumor lines (121 vs. 285 and 272 N. spots $/ 5,000$ cells, respectively; Fig. 3a) suggests that these $\mathrm{T}$ lymphocytes can exhibit specific recognition of a broad panel of TAAs expressed by tumor cells. On the contrary, no recognition of a panel of HLA-A1-restricted peptides (MAG3-A1, MAGE-A3 and COA-1) was observed for the MLTC of patient \#4478D (data not shown). In fact, only for patient \#0342, the MLTC-derived T lymphocytes recognized the HLA-A1-restricted MAGEA3 antigen (data not shown). Thus, this protocol allowed to isolate in vitro MLTCs from 6 out of 6 cutaneous melanoma patients with specific reactivity against the 

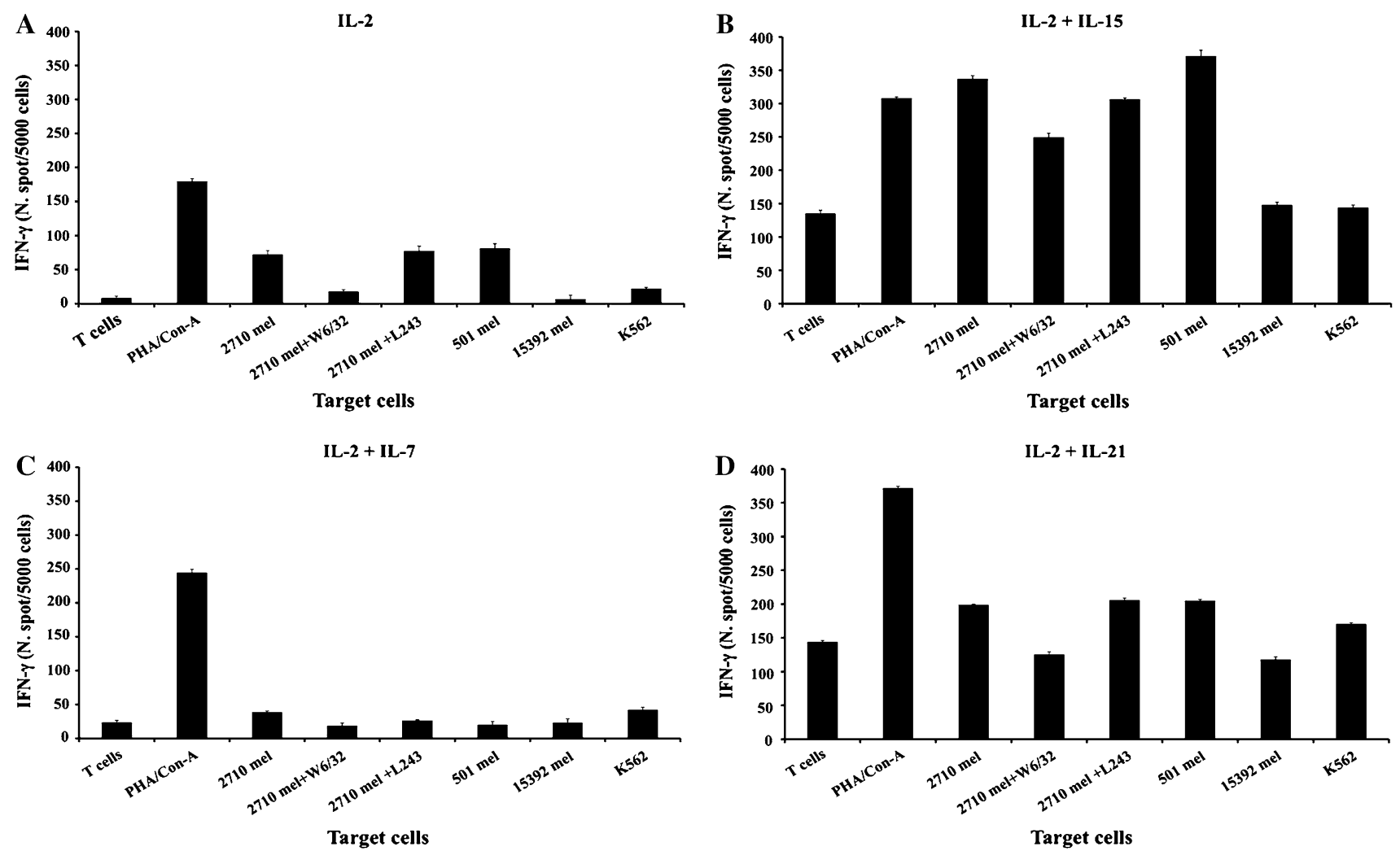

Fig. 2 Tumor-specific recognition of MLTCs from patient \#2710 cultured in vitro in the presence of different cytokines or of their combinations. The specific tumor recognition of lymphocytes isolated from PBMCs of the cutaneous melanoma patient 2710 and cultured for 2 weeks in the presence of different cytokines was analyzed for IFN- $\gamma$ release (ELISPOT assay). IFN- $\gamma$ secretion by T cells was assessed following the incubation with the autologous melanoma line (\#2710 mel)

autologous tumor cells and, in some cases, against allogeneic HLA-matched tumor lines (e.g., 2710, 0342 and DAJU mel). Most of these $\mathrm{T}$ lymphocyte cultures recognized a broad array of TAAs, probably including also unknown antigens, since only in limited cases (\#2710, 0342), the recognition of molecularly defined epitopes was observed. The specificity of anti-tumor reactivity by the isolated MLTCs was corroborated by the lack of the reactivity of HLAmismatched melanoma lines (49318 mel in Fig. 3a) and of the NK target line K562.

We were able to establish in vitro primary uveal melanoma lines with efficiencies approaching 57\% $(\mathrm{N}=8$ tumor cell lines out 12 primary and 2 metastatic ocular tumor samples). Albeit lower than those obtainable for cutaneous melanoma (72\%), it is still higher than expected. We found that the immune profile of these ocular melanoma cell lines was similar to that of cutaneous melanoma counterparts as described in the supplements and Tables 1S and 2S (available online). Thus, we investigated whether our MLTC protocol could also be applied to ocular melanoma patients.

As shown by the representative data for MLTCs 2 in Fig. 3b, these T-cell cultures exerted specific recognition of

pre-treated or not with anti-HLA class I (W6/32) or anti-HLA class II (L243) mAbs. The recognition of the allogeneic HLA-matched (HLA$\left.\mathrm{A} * 0201^{+} 501 \mathrm{mel}\right)$ or HLA-mismatched $(15392 \mathrm{mel})$ melanoma lines and of the NK target cell line K562 was also determined. PHA/Con-A was used as a positive control for IFN- $\gamma$ release. Statistical analysis of differences between means of IFN- $\gamma$ released by $\mathrm{T}$ cells was done by two-tailed $t$ test $(P \leq 0.01)$

the autologous 15765 mel line (236 spots/5,000 cells) with $53 \%$ of inhibition with the anti-MHC class I mAbs (W6/32) (Fig. $3 \mathrm{~b}$ ). We could also isolate $\mathrm{CD} 4^{+} \mathrm{T}$ cells specifically directed against the autologous tumor (\#15765) as shown by the inhibition of IFN- $\gamma$ release by L $243 \mathrm{mAb}$ in MLTC1 (Figure 1S Panel B of supplementary results). These data indicate a preferential $\mathrm{CD} 4^{+}$and $\mathrm{CD} 8^{+} \mathrm{T}$-cell enrichment in MLTC 1 and 2, respectively, as confirmed by the phenotype analysis (61 and $82 \%$ of positive cells, respectively; data not shown). The inhibition of autologous tumor reactivity by $\mathrm{CD}^{+} \mathrm{T}$ lymphocytes (MLTC 2, Fig. 3b) was increased in the presence of both anti-MHC class I and antiNKG2D mAbs (53 vs. $69 \%$ of inhibition) with W6/32 and W6/32 + anti-NKG2D mAbs, respectively), suggesting that the specific recognition of the ocular melanoma cells occurred by the engagement of both TCR and NKG2D as observed for cutaneous melanoma (Fig. 3b). No reactivity directed to known TAAs (Gp100, MAGE-A1 and COA-1) associated with the HLA-A3 molecules expressed by the autologous cells from patient 15765 was detected.

Interestingly, we also observed that these $\mathrm{T}$ lymphocytes exhibited cytotoxic activity, measured by CD107a 


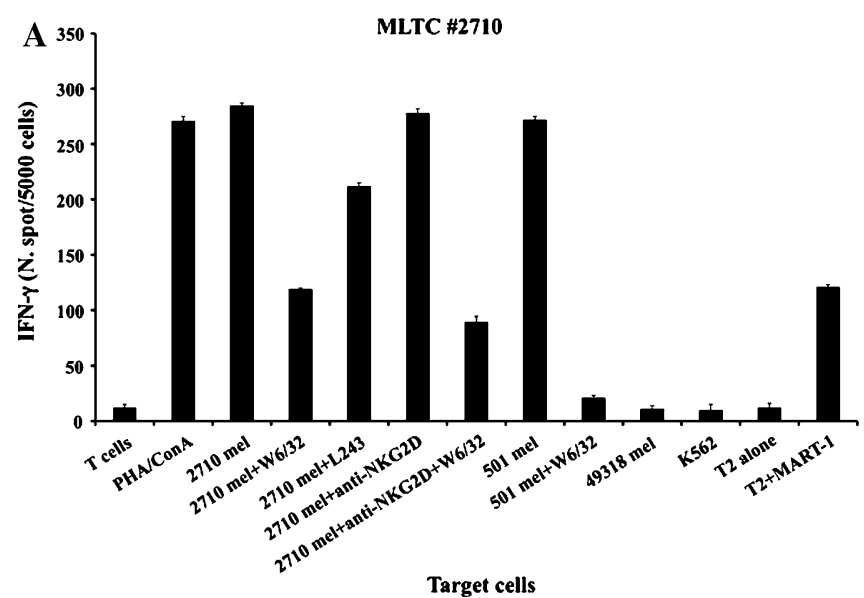

Fig. 3 Isolation of highly tumor reactive T lymphocytes by the MLTC protocol from cutaneous and ocular melanoma patients. PBMC from \#2710 cutaneous and \#15765 ocular melanoma patients were stimulated in vitro with irradiated autologous tumor cells at 1:5 tumor cell lymphocyte ratio in the presence of IL-2 + IL-15. Following 2 weekly stimulations, the tumor specificity of $\mathrm{T}$ cells was assessed by measuring IFN- $\gamma$ secretion (ELISPOT assay) after the incubation with the autologous melanoma cells (\#2710 and \#15765, a, b, respectively) pretreated or not with anti-HLA class I (W6/32) or anti-HLA class II (L243) mAbs. Moreover, T cells were also pre-incubated or not with

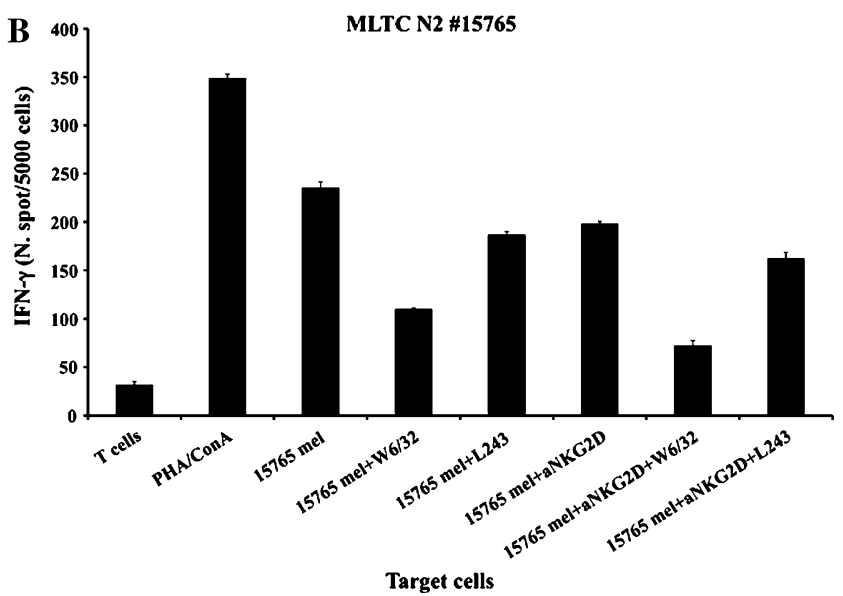

the anti-NKG2D mAb. The recognition of the allogeneic HLAmatched (HLA-A*0201 ${ }^{+} 501$ mel, a) or HLA-mismatched (\#49318 mel, a) melanoma line and of the NK target cell line K562 was also determined. For patient \#2710, the recognition of HLA-A2-restricted TAA-isolated epitopes (Melan-A/MART-1, Panel A and Gp100, SVV-1, COA-1, MAGE-A3, Tyr, data not shown) loaded onto T2 cells was assessed. PHA/Con-A was used as a positive control for IFN- $\gamma$ release. Statistical analysis of differences between means of IFN- $\gamma$ released by $\mathrm{T}$ cells was done by two-tailed $t$ test $(P \leq 0.01)$
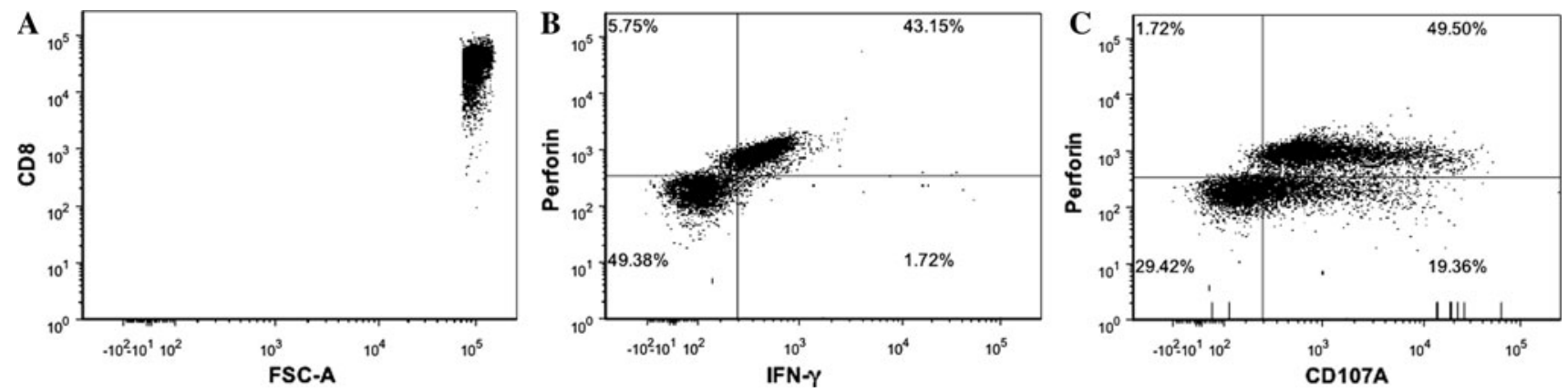

Fig. 4 Cytotoxic activity of the MLTC isolated from the ocular melanoma patient 15765 . The cytotoxic activity against the autologous tumor by the MLTCs from patient 15765 was assessed as CD107a mobilization and the production of perforin and IFN- $\gamma$ (evaluated by immunofluorescence and cytofluorimetric analysis) by $\mathrm{CD} 8^{+} \mathrm{T}$ cells (a logical gate was used to identify $\mathrm{CD}^{+} \mathrm{T}$ cells) following the incuba- tion with the autologous melanoma line $(\mathbf{b}, \mathbf{c})$ or allogeneic HLA-mismatched melanoma lines (501 and $2710 \mathrm{mel}$; data not shown). OKT3 stimulation of $\mathrm{T}$ cells was used as a positive control (data not shown). Data are expressed as \% of positive cells and represent averages of duplicates with $\mathrm{SD} \leq 10 \%$

positive cells) with $\mathrm{CD}^{+} \mathrm{T}$ cells also detectable in the range of $25-51 \%$ of positive cells $(4478 \mathrm{D}$, JOFR, 0342, 7 mel) (representative results from \#2710 patient are shown Fig. 5). These findings are in agreement with the evidence that most of tumor recognition activity is HLA class I-restricted (Figs. 3 and 1S). These T-cell cultures expressed, though to a variable extent (20-40\% of positive cells), some co-stimulatory receptors such as CD28, NKG2D, OX40 (CD134), 4-1BB (CD137), while CD27 was found positive only in $3 / 6$ patients $(4478 \mathrm{D}$, JOFR-IA and DAJU; representative data are shown in Fig. 5). In addition, CCR7 and CD62L were mostly expressed at low levels, and CD57 was not found on these MLTCs (data not shown).
The phenotype analysis of $\mathrm{T}$ lymphocytes following MLTCs from the 6 cutaneous melanoma patients showed a common enrichment of $\mathrm{CD}^{+} \mathrm{CD}^{+} \mathrm{CD}^{+} 5 \mathrm{RO}^{+}$(44-95\% of 

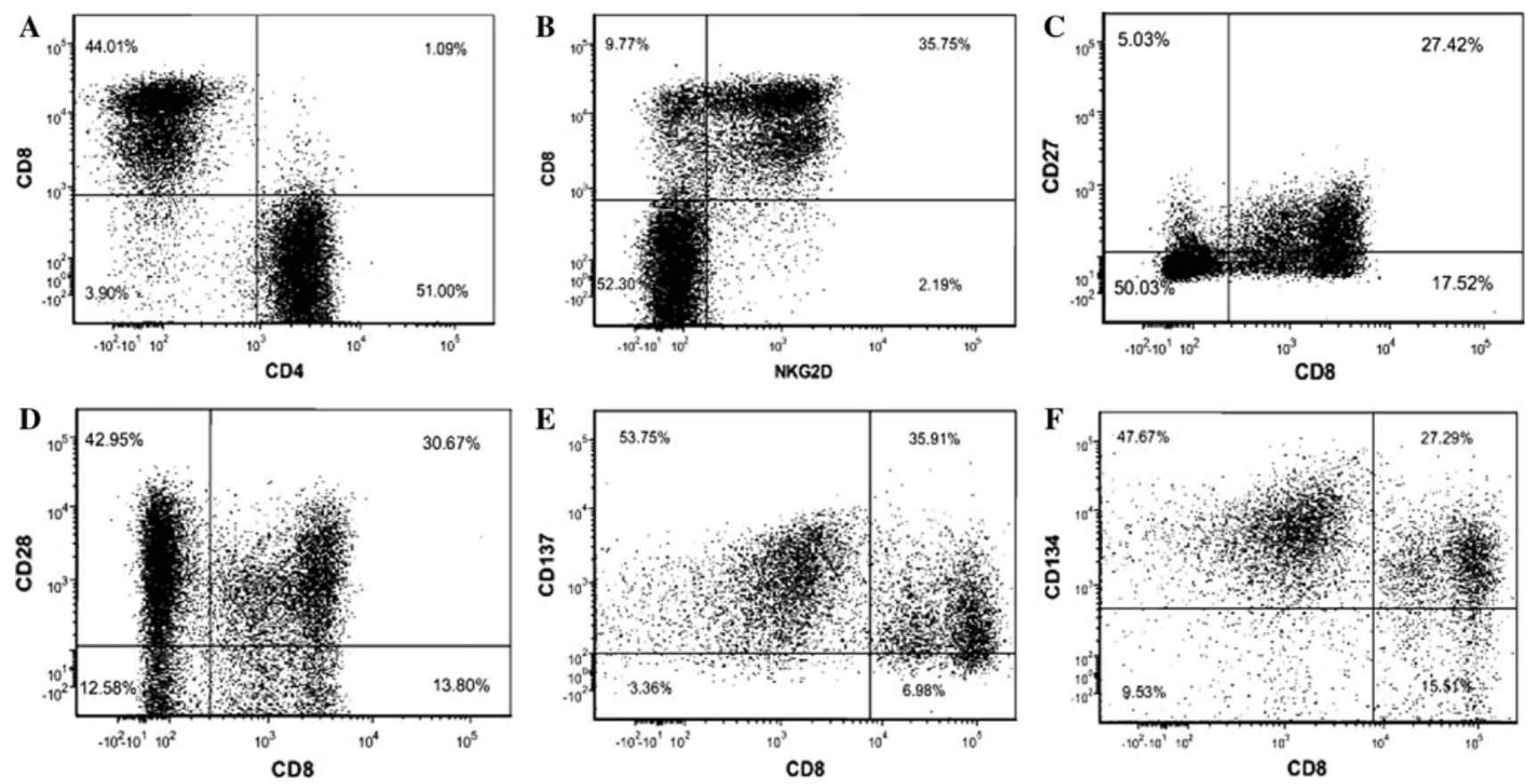

Fig. 5 Phenotype analysis of MLTCs. The phenotype analysis of T lymphocytes isolated in vitro by MLTC before and after REP was assessed by multiparametric IF and cytofluorimetric analysis (see "Materials and methods"). mAbs directed to the following molecules were used: CD3, CD4, CD8, CD45RO, CD45RA, CCR7, CD62L, NKG2D, CD27, CD28, OX40, 41BB, CD25, CD127, CD16, CD56

Therefore, the MLTC-derived T cells we have isolated are in agreement with the phenotype of non-terminally differentiated effector memory $\left(\mathrm{T}_{\mathrm{EM}}\right.$ ) (CD57-negative) $\mathrm{T}$ lymphocytes [33, 34]. Interestingly, $\mathrm{T}$ lymphocytes expressing high levels of co-stimulatory molecules have previously manifested potentially efficient melanoma-specific reactivity and in vivo persistence $[24,25]$.

No $\mathrm{T}$ regulatory (Tregs) cells as identified by specific staining for $\mathrm{CD} 4{ }^{+} \mathrm{CD} 25^{\text {high }} \mathrm{CD} 127^{\text {dim }}$ were found in MLTCs (data not shown).

Of note, a similar phenotype profile was detected for both the MLTC 1 and the MLTC 2 T cells of the ocular melanoma patient 15765 (data not shown).

Thus, non-terminally differentiated anti-tumor $\mathrm{T}_{\mathrm{EM}}$ cells could be ex vivo isolated by applying our protocol to circulating lymphocytes.

Isolation and phenotypic characterization of TILs from cutaneous and ocular melanoma patients

The most encouraging results of ACT protocols for metastatic melanoma patients have been obtained by the use of TILs [20, 21]. Thus, we have carried out a comparison of the phenotype and functional activity between MLTCs and TILs, from both cutaneous and ocular melanoma patients. and CD57. Representative data of T cells (pre-REP MLTC) analysis of patient \#JOFR-IA are represented in the Figure (CD4 vs. CD8 a; CD8 vs. NKG2D, b; CD8 vs. CD27, c; CD8 vs. CD28, Panel d; CD8 vs CD137, e; CD8 vs. CD134, f). Data are expressed as percentage of positive cells

Initially, we isolated TILs from 5 metastatic cutaneous melanoma (3 subcutaneous lesions \#4478D, 9476, 25368 and 2 lymph node lesions \#3681 and 4931, respectively) and from 4 ocular melanoma (3 primary \#3470, 1141, 4022 and one metastatic \#15765) patients. The phenotype analysis of the T lymphocytes is shown in Fig. 6 (cutaneous melanoma patients \# 3681, 4931, 9476 and 25368, panels $\mathrm{A}, \mathrm{B}$ and $\mathrm{C}$ and primary ocular melanoma patients \#3470, 1141 and 4022, panels D, E and F). TILs were cultured in vitro for 5-7 days with $600 \mathrm{IU} / \mathrm{ml}$ of rh-IL-2 in order to enrich $\mathrm{T}$ cells and to remove tumor cell contaminations. These TILs from melanoma were $\mathrm{CD} 8^{+} \mathrm{T}$ cells (46-64\% of positive cells), with $18-60 \%$ of $\mathrm{CD}^{+} \mathrm{T}$ cells (Fig. 6a, d). Only TILs 9476 were enriched for CD4 ${ }^{+} \mathrm{T}$ cells (94\% of positive T cells; panel A). Higher levels of $\mathrm{CD}^{+} \mathrm{T}$ cells (57-80\% of positive cells), with the exception of patient \#1141 (98\% of $\mathrm{CD}^{+} \mathrm{T}$ cells; Fig. 6d), were found in TILs deriving from ocular melanoma lesions. All $\mathrm{T}$ cells expressed homogeneously CD45RO (data not shown) and high levels of CD28 (40-94\% of positive cells; Panels B and E), while CD27 was detected only in TILs from two cutaneous melanoma patients (\#25368 and \#9476, 39 and $46 \%$ of CD8 ${ }^{+}$T cells, respectively; panel B) and in $\mathrm{CD}^{+}$lymphocytes from one ocular melanoma patient (\# 3470, 24\% of CD8 ${ }^{+} \mathrm{T}$ cells; panel E). CD137 was detected at high levels in $\mathrm{T}$ cells from 2 out of 4 
metastatic cutaneous melanoma patients (the 2 lymph node metastatic lesions \#3681 and 4931), in the primary uveal melanoma \#4022 (30\% of $\mathrm{CD}^{+}$cells) (Fig. 6c, f, respectively) and homogeneously in the metastatic ocular melanoma patient \#15765 (CD137 was also present in $100 \%$ of both $\mathrm{CD}^{+}$and $\mathrm{CD} 8^{+}$cells; data not shown). Of note, $10-22 \%$ of $\mathrm{CD} 134^{+} \mathrm{T}$ cells were detected in ocular melanoma TILs (both CD4 and CD8 T cells) and, to a lower extent (10$12 \%$ of positive cells), in cutaneous melanoma deriving $\mathrm{T}$ cells (Fig. 6c, f). CD134 was homogeneously associated with both $\mathrm{CD}^{+}$and $\mathrm{CD} 8^{+} \mathrm{T}$ cells from TILs of \#9476 and \#1141 cutaneous and ocular melanoma patients, respectively (Fig. 6c, f). In addition, for all the patients, $\mathrm{CD} 8^{+} \mathrm{T}$ cells expressed homogenously NKG2D (50-87\% of positive cells) (data not shown). CD57 was detected to a variable extent (11-23\% of positive cells) in subpopulations of both $\mathrm{CD}^{+}$and $\mathrm{CD}^{+} \mathrm{T}$ cells, indicating that most of TILs were not terminally differentiated. No Tregs were found in short-term cultured TILs of all the analyzed cutaneous and ocular melanoma patients (data not shown). Therefore, TILs displayed an effector memory non-terminally differentiated phenotype, and in most cases, lower levels of the expression of co-stimulatory molecules were detected as compared with MLTC-derived T cells (see Figs. 5, 6).

In vivo analysis of the immune infiltrate in ocular melanoma patients

Notably, an immune infiltrate was detected also by IHC analysis in 10 primary ocular melanoma lesions (representative results of patients \#50306324 and 50316250 are shown in the Fig. $6 \mathrm{~g}-\mathrm{n}$ and Figure $2 \mathrm{~S}$ of Supplementary results). In $6 / 10$ tissues, $\mathrm{CD}^{+} \mathrm{T}$ cells were detected (21-70 cells $/ 1 \mathrm{~mm}^{2}$ ); Fig. 6h), while $\mathrm{CD} 8^{+}$enrichment in ocular melanoma tissues was found only in three patients (40-80 cells $/ 1 \mathrm{~mm}^{2}$; Fig. $6 \mathrm{~m}$ ). In addition, heterogeneous levels of Tbet and GATA3 (transcription factors associated with TH1 and TH2 type immune responses, respectively) were observed (Figure $2 \mathrm{~S}$ Panel B, C and F and G). Interestingly, the presence of Tregs (evaluated as $\mathrm{CD} 25^{+} \mathrm{FoxP}^{+}$) was found in association with the enrichment of $\mathrm{CD}^{+}{ }^{+} \mathrm{T}$ cells and with low infiltration of $\mathrm{CD} 8^{+}$ lymphocytes (Fig. 6i, n). High numbers of macrophages with suppressive activity were also observed as shown by the staining with anti-CD163 mAb (Figure 2S Panels D and $\mathrm{H}$ ).

We found that TILs can be detected in primary ocular melanoma lesions, though mostly $\mathrm{CD} 4^{+}$and in association with the presence of Tregs and M2 macrophage, envisioning an immune infiltration possibly dominated by $\mathrm{TH} 2$ and/ or immune suppressive activity.
Functional characterization of TILs isolated

from cutaneous and ocular melanoma patients

The short-term in vitro culture of TILs can, in most cases, rescue their TH1 activity, as suggested by the phenotype analysis (Fig. 6a-f and 2S Panels A-H). To prove this hypothesis, we assessed-when the autologous tumor line was available - the anti-melanoma activity by measuring the IFN- $\gamma$ release (ELISPOT) of TILs from ocular melanoma and compared to that of cutaneous melanoma. Figure 7 shows representative results of TILs from the cutaneous melanoma \#4478D (Panel A) and from the ocular melanoma \#15765 (Panel B) patients. High levels of IFN- $\gamma$ release (355 and 334 spots/5,000 cells for patients \#4478D and \#15765, respectively) were observed following incubation of TILs from both patients with the autologous tumor cell lines. Moreover, the tumor recognition was HLArestricted as the cytokine secretion was inhibited (65 and $58 \%$ for patients \#4478D and \#15765, respectively) by the incubation of tumor cells with the anti-HLA-class I (W6/ 32) mAb, but not by the anti-HLA class II mAb (L243). In addition, both TIL cultures failed to recognize the allogeneic HLA-mismatched melanoma lines (1067 and 15392 lines; Fig. 7). Furthermore, lack of recognition of HLA-A3restricted TAA-derived epitopes (such as Gp100, MAGEA1 and COA-1) was observed for TILs as well as for MLTC isolated from the 15765 patients (data not shown), thus indicating that these $\mathrm{T}$ cells can recognize TAAs specifically associated with ocular melanoma.

These results demonstrate that the short-term in vitro culture of TILs from ocular melanoma can rescue their TH1 activity and that anti-tumor TILs can be isolated from both cutaneous and ocular melanoma patients.

Large number of anti-melanoma $\mathrm{T}$ lymphocytes can be efficiently isolated in vitro by REP of MLTCs

The REP protocol was applied to both MLTC and TILs isolated from 10 cutaneous and ocular melanoma patients in order to determine whether comparable expansion in vitro of effector $\mathrm{T}$ cells could be obtained. The results shown in Fig. 8 indicate that efficient expansion $\left(68-148 \times 10^{6} \mathrm{~T}\right.$ cells) of TILs (\#15765 and \#4478D) and MLTCs (\#4478D, \#2710 and \#0342) could be achieved with an increase value of 240-592 times (Fig. 8, insert). Notably, similar expansion of T lymphocytes was observed in TILs vs MLTCs of the same patient (\#4478D) (240 and 272 times number, respectively) (insert of Fig. 8). Moreover, an efficient expansion of TILs from the ocular melanoma patient \#15765 was achieved $\left(8.4 \times 10^{7}\right.$ cells starting from $1.5 \times 10^{5}$ cells with an increase of 560 times) as well, thus indicating that the possible anergic state of $\mathrm{T}$ cells isolated 

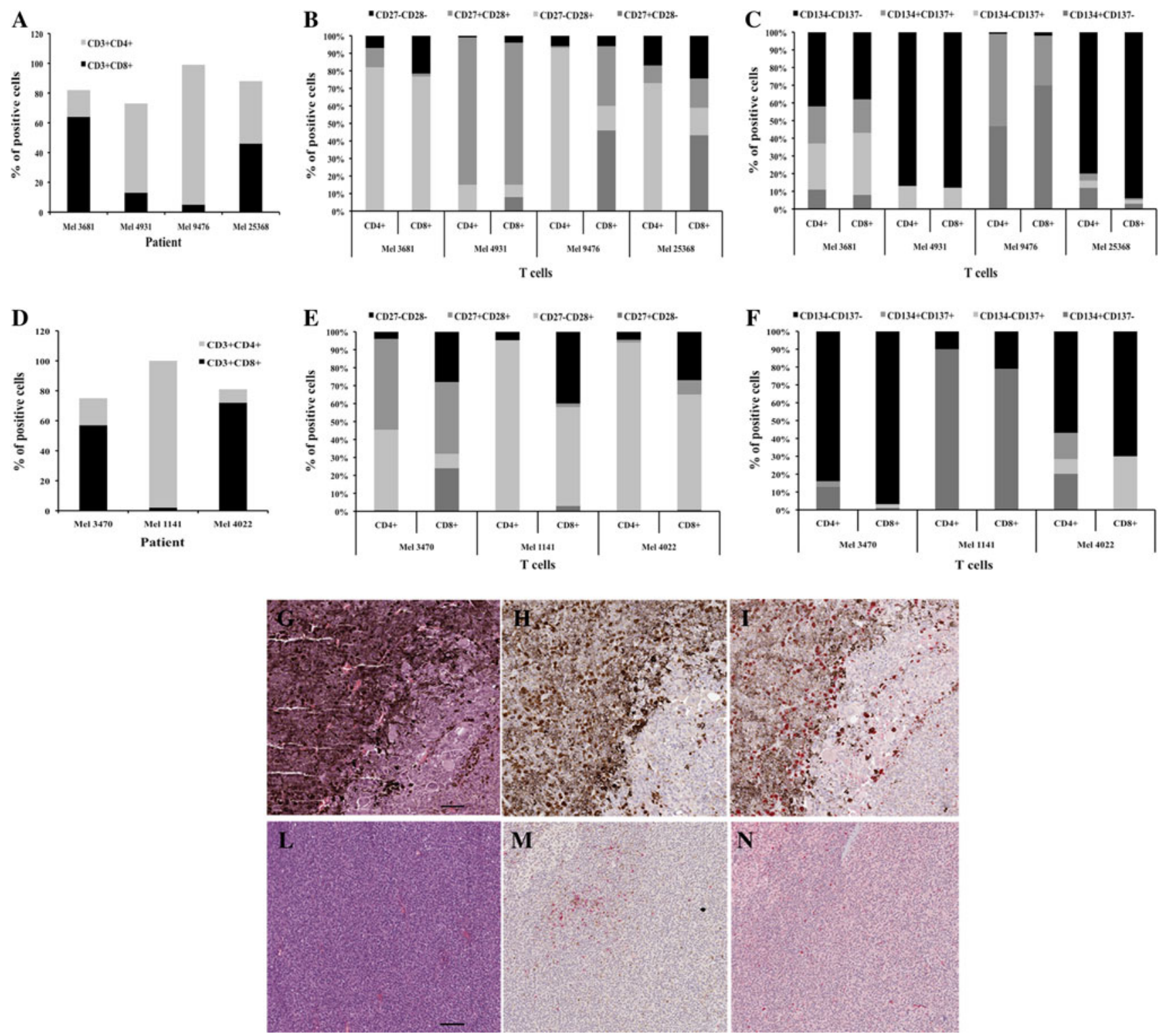

Fig. 6 Characterization TILs isolated from both cutaneous and ocular melanoma patients. TILs isolated by the mechanical processing of surgically resected tumor lesions $(\mathrm{N}=4$ metastatic cutaneous melanoma and $\mathrm{N}=3$ primary ocular melanoma patients) were cultured for 5-7 days in X-Vivo-15 plus 5\% HS and $600 \mathrm{IU} / \mathrm{ml}$ of rh-IL-2 in order to enrich $\mathrm{T}$ cells and to remove tumor cell contaminations. IF and cytofluorimetric analysis was carried out according the procedures indicated in "Materials and methods". mAb directed to the following molecules were used: CD3, CD4, CD8, CD45RO, CD45RA, CCR7,

from ocular suppressive tumor milieu can be recovered ex vivo and such lymphocytes efficiently expanded.

The specific anti-tumor reactivity by MLTC-derived T lymphocytes expanded in vitro in large scale with the use of the REP protocol [31] was obtained for all of the 7 cutaneous or ocular melanoma patients (\# 7, 2710, 0342, 4478D, DAJU-1A, JOFR and 15765). Representative results of patients 4478D and DAJU are shown in Figure 3S Panels A and B, respectively, of supplementary online results). Simi-
CD62L, NKG2D, CD27, CD28, OX40, 41BB, CD25, CD127, CD16, CD56, CD57. Representative results of CD4, CD8, CD27, CD28, CD134 and CD137 are shown. Data are expressed as percentage of positive cells (a-f). IHC analysis of the immune infiltration in ocular melanoma patients was carried out $(\mathbf{g}-\mathbf{n})$. CD4 (brown staining)/CD8 (red staining) $(\mathbf{h}, \mathbf{m})$ and FOXP3 (brown)/CD25 (red) $(\mathbf{i}, \mathbf{n})$ in two ocular melanoma tissues (\# 050306324-0503161250). Hematoxylin/ eosin staining is shown in $\mathbf{g}, \mathbf{l})$. The scale bars represent $100 \mu \mathrm{m}$. Magnification $\times 10$

lar results were obtained for the TILs isolated from three patients (\# 4478D, 25368 and 15765) following the application of the REP as shown by the representative results in Figure 4S of Supplementary (available online). In addition, both MLTC- and TIL-derived T cells following the application of REP maintained their phenotype observed prior to the large scale expansion (data not shown).

In conclusion, our results indicate that, similarly to TILs that have been thus far largely used for ACT studies [20], 


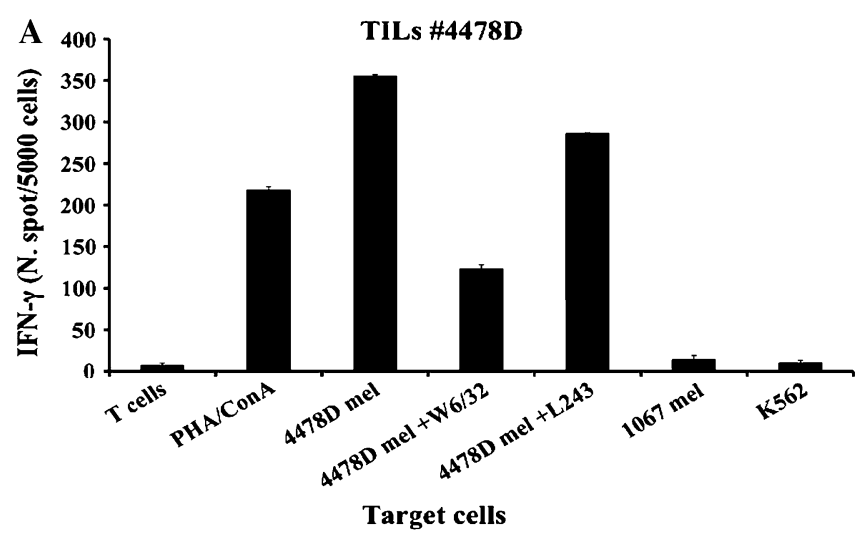

Fig. 7 Functional activity of TILs isolated from cutaneous and ocular melanoma patients. TILs isolated from the mechanical processing of surgically resected tumor lesions were cultured for 5-7 days in $\mathrm{X}$-Vivo- 15 plus $5 \% \mathrm{HS}$ and $600 \mathrm{IU} / \mathrm{ml}$ of rh-IL-2 in order to enrich T cells and to remove tumor cell contaminations. The tumor recognition of these TILs was assessed by measuring IFN- $\gamma$ release (ELISPOT assay) after the incubation with the autologous melanoma cells (the cutaneous melanoma \#4478D mel and the ocular melanoma \#15765 mel,

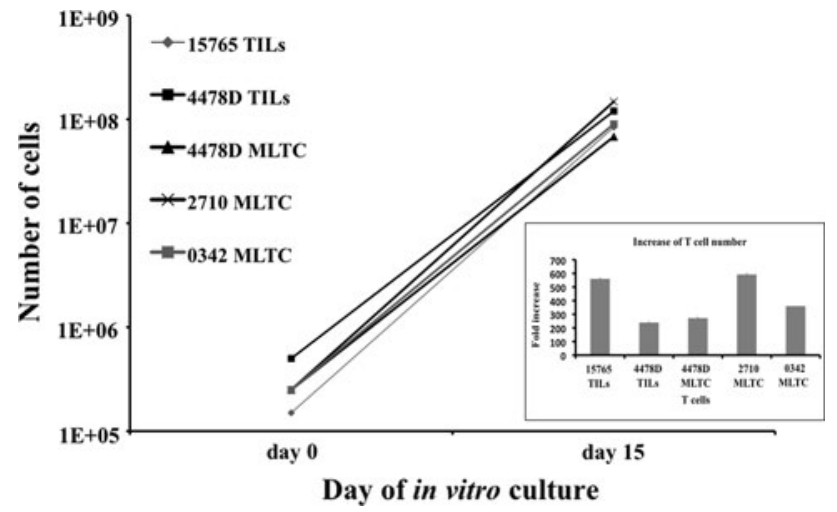

Fig. 8 Efficiency of expansion in vitro of anti-tumor T cells from both MLTCs and TILs. T cells from MLTCs or TILs of cutaneous and ocular melanoma patients were stimulated in vitro by REP in the presence of irradiated (50 Gy) allogeneic PBMCs from 3 healthy donors plus OKT3 (30 ng/ml), and at day 4, 6,000 IU/ml of rh-IL-2 was added. Fresh medium with $6,000 \mathrm{IU} / \mathrm{ml}$ of rh-IL-2 was replaced every 3 days. After 15 days of in vitro culture, the growth of $\mathrm{T}$ cells was evaluated. Data are represented as cell number and are the mean of three independent experiments with $\mathrm{SD} \leq 10 \%$. In the insert, the fold increase number of these $\mathrm{T}$-cell cultures is indicated

the protocol we have identified based on MLTC followed by REP can lead to the isolation of large numbers of effector $\mathrm{T}$ cells. This protocol appears then to be suitable for ACT clinical applications for cutaneous and, for the first time, for ocular melanoma patients.

\section{Discussion}

ACT represents a promising therapeutic approach for metastatic melanoma. In fact, the infusion in metastatic patients

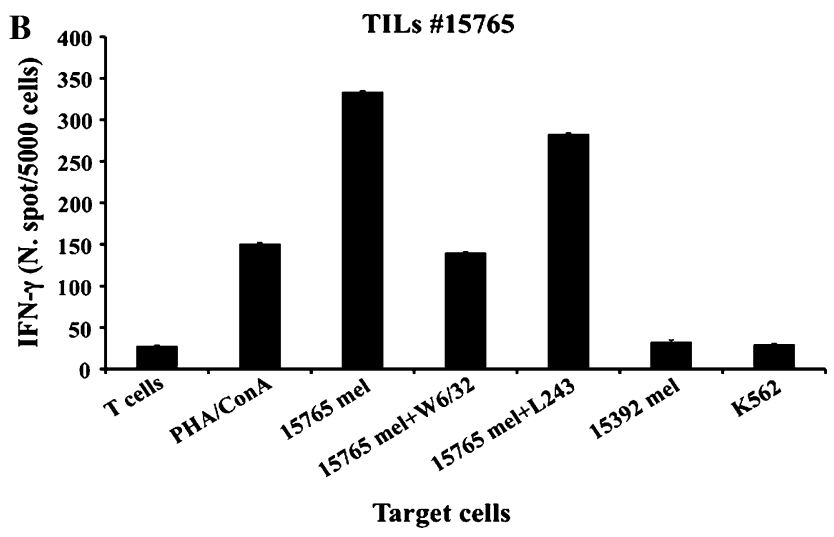

a, b, respectively) pre-treated or not with anti-HLA class I (W6/32) or anti-HLA class II (L243) mAbs. The recognition of the allogeneic HLA-mismatched (1067 mel, a) or of the allogeneic HLA-matched (HLA-A $3^{+} 15392$ mel, b) melanoma lines and of the NK target cell line K562 was also determined. PHA/Con-A was used as a positive control for IFN- $\gamma$ release. Statistical analysis of differences between means of IFN- $\gamma$ released by T cells was done by two-tailed $t$ test $(P \leq 0.01)$

of autologous TILs has led to significant responses in a high number of clinical cases [20,21]. A multicenter confirmatory trial has been proposed to show that this complex technique of ex vivo expansion of TILs can be applied by multiple institutions [35]. In addition, a simplified protocol for the isolation and the growth in vitro of TILs has been set up to improve both the efficiency of isolation of these $\mathrm{T}$ lymphocytes and their anti-tumor potential for ACT studies $[26,36]$. Nevertheless, some features such as age, sex, tumor location and any prior systemic therapy of patients can affect the success in TIL isolation [22]. Therefore, we sought to identify an alternatively protocol, when TILs are not available, which involves the isolation of polyclonal anti-melanoma $\mathrm{T}$ lymphocytes from the PBMCs of both cutaneous and ocular melanoma patients. We have successfully and reproducibly (7/7 patients) isolated anti-tumor circulating $\mathrm{T}$ cells by the stimulation in vitro of PBMCs with irradiated autologous tumor cells (MLTCs; Fig. 3 and also Figure 1S of supplementary online data). The MLTCs cultures isolated in vitro corresponded to non-terminally differentiated $\mathrm{T}_{\mathrm{EM}}[33,34]$ expressing high levels of costimulatory molecules, a subpopulation of $\mathrm{T}$ cells that can exhibit efficient melanoma-specific reactivity and in vivo persistence $[24,25]$.

In few cases (2/6), we could also molecularly identify the TAAs (Melan-A/MART-1 and MAGE-A3) recognized by the tumor-specific MLTC T cells. Nevertheless, the cytokine release in the presence of the autologous tumor recognition was higher compared to the TAA-directed reactivity, suggesting that our protocol can achieve an ex vivo enrichment of $\mathrm{T}$ lymphocytes reacting to multiple TAAs, thus avoiding the selection of tumor immune variants. Along this line, it has been documented that TILs, reactive 
with a broad array of TAAs, isolated from melanoma patients can be successfully exploited for ACT [20, 37, 38], possibly targeting the heterogeneity of tumor cells.

Very little information is available on the immune-mediated control of ocular melanoma [10, 11], and in addition, this aggressive disease has limited therapeutic options [7, 8]. Therefore, immunotherapy-based treatment, as ACT, can represent a promising approach for the control of this disease. Interestingly, the application of our MLTC-based protocol has led to the isolation ex vivo of tumor reactive $\mathrm{T}$ cells from one ocular metastatic melanoma patient (Fig. 3 and Figure 1S of supplementary data). In addition, the phenotype of these $\mathrm{T}$ cells was of $\mathrm{T}_{\mathrm{EM}}$ type with the expression of high level of co-stimulatory molecules, similarly to MLTCs from cutaneous melanoma patients (data not shown and Fig. 5). Of note, these $\mathrm{T}$ cells, in addition to IFN- $\gamma$ secretion (Figs. 3 and $1 \mathrm{~S}$ ), exerted cytotoxic activity (Figs. 4) against the autologous tumor cells. Similar data were obtained for cutaneous melanoma-derived MLTCs (data not shown). Ocular melanoma is a rare disease, and therefore, the availability of tumor cell lines and PBMCs in an autologous setting is limited. However, our encouraging results demonstrate a potential future wider exploitation of our protocol that can be of benefit also for these melanoma patients. Since we could not molecularly identify the TAAs recognized by the anti-ocular melanoma MLTC cultures, we will further characterize these immune responses exploiting $\mathrm{T}$ cells as probes for the molecular cloning of the target molecule.

In order to determine whether our MLTC-derived immune responses could be exploited for ACT protocols, we have compared their anti-tumor activity and phenotype with those of TILs. We have isolated TILs from both cutaneous $(\mathrm{N}=5)$ and ocular $(\mathrm{N}=4)$ melanoma patients and found that they specifically exerted autologous tumor recognition (representative data are shown in Fig. 7). The phenotype analysis showed that non-terminally differentiated $\mathrm{T}_{\mathrm{EM}}$ can be isolated from both TILs and MLTCs. However, higher levels of co-stimulatory molecules were found in MLTC lymphocytes, suggesting that efficient anti-tumor activity and persistence in vivo can be associated with MLTCs rather than with TILs.

By IHC, we also analyzed the presence in vivo of the immune infiltrate in 10 ocular melanoma surgical samples, where we could detect TILs in 9/10 tissues, mostly CD4 ${ }^{+} \mathrm{T}$ cells (6/10 tissues). Only 3 cases showed high numbers of $\mathrm{CD} 8^{+}$lymphocytes. We found an heterogeneous expression of TH1 and TH2 type T cells, while the detection of $\mathrm{CD} 25^{+}$ and $\mathrm{FOXP}^{+}$Treg cells was directly associated with high level of CD4. Moreover, in all of the analyzed samples (10/ 10), high levels of $\mathrm{CD} 163^{+}$macrophages were observed. The presence of these cells in tumor tissues has been described to be correlated with poor prognosis and with suppressive immune functions [39, 40]. Therefore, our observations indicate that ocular melanoma potentially represent an immune suppressive environment, in accord with previous published data $[9,10]$, and similarly to cutaneous melanoma $[13,14]$. However, the ex vivo short-term culture of TILs can rescue their anti-tumor activity (Fig. 7). Thus far, with our protocol based on the ex vivo enrichment of circulating T cells (MLTCs), we have demonstrated that we can overcome the anergic state of $\mathrm{T}$ cells induced by the tumor milieu.

We obtained a remarkable high frequency of both longterm (perpetual) and short-term (1-4 months) cell lines in 72 and $57 \%$ cutaneous and ocular melanoma, respectively. A low rate of TILs isolation (38\%) was observed from our cutaneous melanoma patients as compared to the previous published results $(60-70 \%)$ [20, 22]. This difference may depend on the limited population size we have analyzed and/or on the small dimensions $(0.5-1.5 \mathrm{~cm}$ diameter) of the tumor fragments we have received. In ocular melanoma, there are no documented studies involving the isolation of TILs on a large patient base. Nevertheless, we were able to isolate and successfully culture TILs in $28.5 \%$ of our patients. Thus, our data indicate that the application of the MLTC method, which is based on tumor cell availability, can be of interest since it is applicable to a large number of melanoma patients from whom TILs cannot be obtained and, in addition, to ocular melanoma subjects for whom few studies documenting TIL isolation and characterization are available $[9,12]$.

Notably, the REP stimulation [31] applied to the in vitro isolated MLTCs indeed led to the successful expansion of these $\mathrm{T}$ cells (Fig. 8). The final number of $\mathrm{T}$ cells obtained from MLTCs was comparable to that of TILs (Fig. 8); moreover, we also demonstrated that after the REP, these T lymphocytes retained their initial specific anti-tumor activity (Figure $3 \mathrm{~S}$ of supplementary data available online). Thus, we identified a new protocol that allows the isolation of large number (2-10 billions) of $\mathrm{T}$ lymphocytes to be infused in melanoma patients.

Durable clinical responses have been recently documented in stage IV melanoma patients infused with polyclonal anti-tumor PBMCs, pre-stimulated in vitro with the autologous tumor cells, and given in combination with lowdose IFN- $\alpha$ [41]. This indicates that by the exploitation of the immunogenicity of tumor cells, it is possible to efficiently isolate and direct systemic anti-tumor immune responses against the residual tumor cells.

A limitation of our approach is the availability of autologous tumor cells, although as we have shown above (Figs. 3 and 1S of supplementary results) that short-term cultured melanoma cells can be used. Alternatively, to overcome the lack of autologous tumor cell lines, HLAmatched/-semimatched allogeneic melanoma lines could be 
used as stimulators of PBMCs. Indeed, tumor reactive TILs have been selected ex vivo by the usage of allogeneic tumor cells as stimulators [42].

Altogether, we have carried out a detailed characterization of immune responses of $\mathrm{T}$ cells from the peripheral blood vs tumor tissues of both cutaneous and ocular melanoma patients that allowed us identifying a novel MLTCbased protocol to isolate and successfully expand ex vivo polyclonal anti-tumor circulating $\mathrm{T}$ cells. In addition, our protocol can overcome the possible anergic state of TILs due to the immunesuppressive tumor environment. We envision that our method may be suitable for ACT protocols, when TILs are not available, for both cutaneous and ocular melanoma patients.

Acknowledgments We are indebted with Mrs Gloria Sovena (Unit of Immuno-biotherapy of Melanoma and Solid Tumors, San Raffaele Scientific Institute, Milan, Italy) for the technical assistance in the establishment in vitro of melanoma lines and the isolation and expansion of T lymphocytes and with Mrs Ylenia Papa (Unit of Pathology, San Raffaele Hospital, Milan, Italy) for assistance in tissue preparation and staining for IHC analysis. We thank Dr. Katherina Fleischhauer (Unit of Molecular and Functional Immunogenetics, San Raffaele Scientific Institute, Milan, Italy) for the HLA typing analysis of cancer patients, Dr. G.C. Spagnoli (Institute of Surgical Research and Hospital Management, University Hospital, Basel, Switzerland) for providing the anti-MAGE 57B and 6C1 mAbs, and Dr. Pierre Coulie (de Duve Institute, Université Catholique de Louvain, Brussels, Belgium) for providing the JOFR-1A and DAJU melanoma cell lines and PBMCs. We thank Dr. Alessio Palini Unit of Cytometry, San Raffaele Scientific Institute, Milan, Italy for the editorial revision of the manuscript. This work was supported by the Italian Association for Cancer Research (Milan) and by the Alliance against Cancer Project 3 (Rome), Grant to G. Parmiani.

Conflict of interest The authors declare that they have no conflict of interest.

Open Access This article is distributed under the terms of the Creative Commons Attribution Noncommercial License which permits any noncommercial use, distribution, and reproduction in any medium, provided the original author(s) and source are credited.

\section{References}

1. American Cancer Society. Cancer facts \& figures 2009 (2010) http://www.cancer.org/downloads/STT/500809web.pdf. Accessed June 4, 2010

2. Tsao H, Atkins MB, Sober AJ (2004) Management of cutaneous melanoma. N Engl J Med 351:998-1012 [Erratum, N Engl J Med 2004;351:2461.]

3. Chapman PB, Hauschild A, Robert C, Haanen JB, Ascierto P, Larkin $J$ et al (2011) Improved survival with Vemurafenib in melanoma with BRAF V600E mutation. New Engl J Med June 5 [Epub ahead of print]

4. Robert C, Thomas L, Bondarenko I, O'Day S, Weber J, Garbe C et al (2011) Ipilimumab plus dacarbazine for previously untreated metastatic melanoma. New Engl J Med (June 6 [Epub ahead of print])

5. Schwartzentruber DJ, Lawson DH, Richards JM, Conry RM, Miller DM, Treisman J et al (2011) gp100 peptide vaccine and interleukin-2 in patients with advanced melanoma. N Engl J Med 364:2119-2127

6. Desjardins L, Levy-Gabriel C, Lumbroso-Lerouic L, Sastre X, Dendale R, Couturier J et al (2006) Prognostic factors for malignant uveal melanoma. Retrospective study on 2,241 patients and recent contribution of monosomy-3 research. J Fr Ophtalmol 29:741-749

7. Augsburger JJ, Correa ZM, Shaikh AH (2009) Effectiveness of treatments for metastatic uveal melanoma. Am J Ophthalmol 148:119-127

8. Patel M, Smyth E, Chapman PB, Wolchok JD, Schwartz GK, Abramson DH et al (2011) Therapeutic implications of the emerging molecular biology of uveal melanoma. Clin Cancer Res 17:2087-2100

9. McKenna KC, Chen PW (2010) Influence of immune privilege on ocular tumor development. Ocular Immunol Inflamm 18:80-90

10. Egan RM, Yorkey C, Black R, Loh WK, Stevens JL, Woodwrd JG (1996) Peptide-specific T cell clonal expansion in vivo following immunization in the eye, an immune-privileged site. J Immunol 157:2262-2271

11. Niederkorn JY, Streilein JW (1983) Intracamerally induced concomitant immunity: mice harboring progressively growing intraocular tumors are immune to spontaneous metastasis and secondary tumor challenge. J Immunol 131:2587-2594

12. Niederkorn JY, Streilein JW (1984) Adoptive transfer of immunity to intraocular tumors in mice. Invest Ophtalmol Vis Sci 25:336342

13. Ilkovitch D, Lopez D (2008) Immune modulation by melanomaderived factors. Exper Dermatol 17:977-985

14. Gajewski TF (2011) Molecular profiling of melanoma and the evolution of patient-specific therapy. Semin Oncol 38:236-242

15. Rosenberg SA (2000) Identification of cancer antigens: impact on development of cancer immunotherapies. Cancer J 6(Suppl 3):S200-S207

16. Parmiani G, Castelli C, Santinami M, Rivoltini L (2007) Melanoma immunology: past, present and future. Curr Opin Oncol 19:121-127

17. Lucas S, Coulie PG (2008) About human tumor antigens to be used in immunotherapy. Semin Immunol 20:301-307

18. Boon T, Coulie PG, Van den Eynde BJ, van der Bruggen P (2006) Human $\mathrm{T}$ cell responses against melanoma. Annu Rev Immunol 24:175-208

19. Kessels HWG, Wolkers MC, Schumacher TNM (2002) Adoptive transfer of T-cell immunity. Trends Immunol 23:264-269

20. Rosenberg SA, Dudley M (2009) Adoptive cell therapy for the treatment of patients with metastatic melanoma. Curr Opin Immunol 21:233-240

21. Rosenberg SA, Yang JC, Sherry RM, Kammula US, Hughes MS, Phan GQ et al (2011) Durable complete responses in heavily pretreated patients with metastatic melanoma using $\mathrm{T}$ cell transfer immunotherapy. Clin Cancer Res [Epub ahead of print]

22. Joseph RW, Peddareddigari VR, Liu P, Miller P, Overwijk W, Bekele BN et al (2011) Impact of clinical and pathologic features on tumor-infiltrating lymphocyte expansion from surgically excised melanoma metastases for adoptive T-cell therapy. Clin Cancer Res [Epub ahead of print]

23. Zhou J, Shen X, Huang J, Hodes RJ, Rosenberg SA, Robbins PF (2005) Telomere length of transferred lymphocytes correlates with in vivo persistence and tumor regression in melanoma patients receiving cell transfer therapy. J Immunol 175:7046-7052

24. Huang J, Khong HT, Dudley ME, El-Gamil M, Li YF, Rosenberg SA et al (2005) Survival, persistence, and progressive differentiation of adoptively transferred tumor-reactive $\mathrm{T}$ cells associated with tumor regression. J Immunother 28:258-267

25. Hernandez-Chacon JA, Li Y, Wu RC, Bernatchez C, Wang Y, Weber JS et al (2011) Costimulation through the CD137/4-1BB 
pathway protects human melanoma tumor-infiltrating lymphocytes from activation-induced cell death and enhances antitumor effector function. J Immunother 34:236-250

26. Besser MJ, Shapira-Frommer R, Treves AJ, Zippel D, Itzhaki O, Hershkovitz L et al (2010) Clinical responses in a phase II study using adoptive transfer of short-term cultured tumor infiltration lymphocytes in metastatic melanoma patients. Clin Cancer Res 16:2646-2655

27. Morgan RA, Dudley ME, Rosenberg SA (2010) Adoptive cell therapy: genetic modification to redirect effector cell specificity. Cancer J 16:336-341

28. Bonini C, Brenner MK, Heslop HE, Morgan RA (2011) Genetic modification of $\mathrm{T}$ cells. Biol Blood Marrow Transp 17(1 Suppl):S15-S20

29. Maccalli C, Di Cristanziano V, Fodale V, Corsi D, D'Agostino G, Petrangeli $V$ et al (2008) Induction of both CD8 + and CD4 + Tcell mediated responses in colorectal cancer patients by colon antigen-1. Clin Cancer Res 14:7292-7303

30. Novellino L, Castelli C, Parmiani G (2005) A listing of human tumor antigens recognized by T cells: March 2004 update. Cancer Immunol Immunother 54:187-207

31. Dudley ME, Wunderlich JR, Yang JC, Sherry RM, Topalian SL, Restifo NP et al (2005) Adoptive cell transfer therapy following non-myeloablative but lymphodepleting chemotherapy for the treatment of patients with refractory metastatic melanoma. J Clin Oncol 23:2346-2357

32. Aktas E, Kucuksezer UC, Bilgic S, Erten G, Deniz G (2009) Relationship between CD107a expression and cytotoxic activity. Cell Immunol 254:149-154

33. Sallusto F, Geginat J, Lanzavecchia A (2004) Central memory and effector memory $\mathrm{T}$ cell subsets: function, generation, and maintenance. Annu Rev Immunol 22:745-763

34. Sallusto F, Lanzavecchia A, Araki K, Ahmed R (2010) From vaccines to memory and back. Immunity 33:451-463
35. Weber J, Atkins M, Hwu P, Radvanyi L, Sznol M, Yee C (2011) Immunotherapy task force of the NCI investigational drug steering committee. White paper on adoptive cell therapy for cancer with tumor-infiltrating lymphocytes: a report of the CTEP subcommittee on adoptive cell therapy. Clin Cancer Res 17:1664-1673

36. Tran KQ, Zhou J, Durflinger KH, Langhan MM, Shelton TE, Wunderlich JR, Robbins PF et al (2008) Minimally cultured tumorinfiltrating lymphocytes display optimal characteristics for adoptive cell therapy. J Immunother 31:742-751

37. Dudley ME, Wunderlich JR, Shelton TE, Even J, Rosenberg SA (2003) Generation of tumor-infiltrating lymphocyte cultures for use in adoptive transfer therapy for melanoma patients. J Immunother 26:332-342

38. Khong HT, Wang QJ, Rosenberg SA (2004) Identification of multiple antigens recognized by tumor-infiltrating lymphocytes from a single patient: tumor escape by antigen loss and loss of MHC expression. J Immunother 27:184-190

39. Burt BM, Rodig SJ, Tilleman TR, Elbardissi AW, Bueno R, Sugarbaker DJ (2011) Circulating and tumor-infiltrating myeloid cells predict survival in human pleural mesothelioma. Cancer [Epub ahead of print]

40. Komohara Y, Hasita H, Ohnishi K, Fujiwara Y, Suzu S, Eto M et al (2011) Macrophage infiltration and its prognostic relevance in clear cell renal cell carcinoma. Cancer Sci 10:1424-1431

41. Verdegaal EM, Visser M, Ramwadhdoebé TH, van der Minne CE, van Steijn JA, Kapiteijn E et al (2011) Successful treatment of metastatic melanoma by adoptive transfer of blood-derived polyclonal tumor-specific $\mathrm{CD} 4^{+}$and $\mathrm{CD} 8^{+} \mathrm{T}$ cells in combination with low-dose interferon-alpha. Cancer Immunol Immunother 60:953963

42. Carlsson B, Sadeghi A, Bengtsson M, Wagenius G (2008) Effector $\mathrm{T}$ cell analysis of melanoma tumor-infiltrating lymphocyte cultures using HLA-ABC semimatched melanoma cell lines. J Immunother 31:633-643 